\section{POPULAR FOR PERIODONTAL POCKETS}

Delegates visiting stand K13 at BDTA Dental Showcase will witness the wonders of the Waterpik Cordless Plus Water Flosser - formerly known as the dental water jet.

The Cordless Plus Water Flosser is a clinically proven alternative to traditional interdental and subgingival cleaning methods such as string floss and can significantly reduce the causes of periodontal disease.

Visitors to the Waterpik stand will also be able to see the Pik Pocket Tip, which helps to clean periodontal pockets.

Waterpik products have proved popular with practitioners and patients alike and are now widely available on the high street.

Reader response number 60

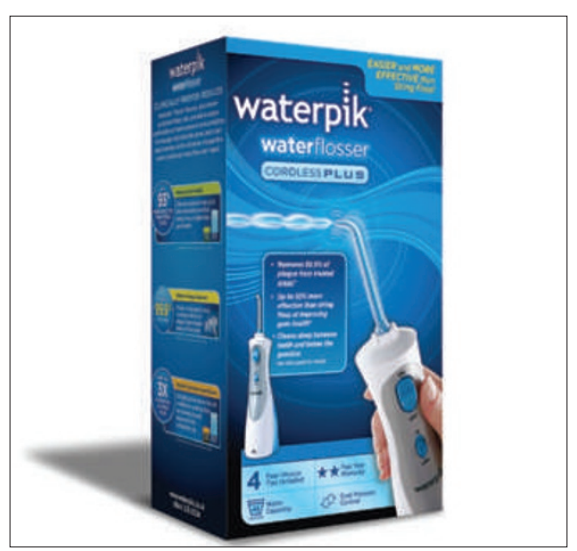

\section{YOUR FINANCIAL FUTURE}

Since 1996 DPAS has provided cost effective administration services for dentists who want to offer maintenance plans, memberships plans and children's plans while maintaining and promoting the integrity of their own practice brand.

DPAS will help you create and establish a plan specifically designed around your patients' needs, using your own practice branding to help further establish your position within an increasingly competitive market, safeguarding your income and ultimately increasing the value of your practice.

DPAS can support you whether you are considering conversion from the NHS or working within an established practice or mixed practice. To learn more about retaining and attracting patients and securing your practice's finances, visit stand R01 at Dental Showcase.

Reader response number 63

\section{BE ENLIGHTENED ABOUT COMPOSITES}

On stand K14 at BDTA Dental Showcase, Evident's consultants will be busy demonstrating their custom-made loupes by leading supplier ExamVision.

ExamVision loupes and lights offer dental professionals considerable choice in versions, colours and magnifications including the newly developed short barrel $4.2 \mathrm{x}$ magnification loupe, the lightest and most balanced high magnification loupe on the market.

Evident will also be demonstrating their consumable products, most of which are from leading US dental company Danville. These include Prelude, a system for dentine and enamel bonding; Accolade SRO, a super radio-opaque, flowable composite; and the Accolade PV veneer placement system. The latter is unique as both the try-in paste and the flowable composite use the same material. The colour matched try-in pastes are an ultra slow setting version of the flowable composite and do not need to be completely removed before bonding. Reader response number 64 